\title{
The Relative Efficiency of Saudi Banks: Data Envelopment Analysis Models
}

\author{
Mohammad Abdelkarim ALMUMANI
}

\author{
Department of Administrative Sciences-Finance Section, King Saud University-RCC \\ P.O.Box 28095, Riyadh 11437, Kingdom of Saudi Arabia \\ E-mail:malmumani@ksu.edu.sa, Mobile:00966565167537
}

\begin{abstract}
The purpose of this study is to measure the relative efficiency of banks in Saudi Arabia using a basic $D E A$ models like CCR and BCR. Also, it investigated the determinants of such efficiency in terms of bank size and capitalization. The duration of the measured performance of the Saudi banking sector is (2007-2011). The results indicate that, on a relative scale, Saudi banks were efficient in the management of their financial resources. In addition, it was found that efficiency score of the selected banks is high and stable over time and the management of the banks consistently improved their efficiency during the period. Another important result is that the relative efficiency of Saudi smaller banks significantly outperforms much better than medium and larger size banks. However, banks with higher capital adequacy ratio are less efficient. Thus, banks in Saudi Arabia with higher capital adequacy ratio are less risky, managing safer and lower-earning portfolios. This study provides a starting point for further investigation and validation into the efficiency of the Saudi banking sector; also it can provide important information for policy makers as for the openness of Saudi new banks. Therefore, more investigation with alternative models are required.

Key words Saudi Banking Efficiency, Saudi Financial System, data Envelopment Analysis, Technical Efficiency, Scale Efficiency

DOI: 10.6007/IJARAFMS/v3-i3/115

URL: http://dx.doi.org/ 10.6007/IJARAFMS/v3-i3/115
\end{abstract}

\section{Introduction}

One of the major issues which were raised among developing nations, and indeed all economies is how to improve their technical efficiency. This has led to the adoption of various economic systems and policy options. The Saudi economy in general and the banking sector in particular is not an exception to this. This is more so when banks, like most other production entities are profit oriented. The efficient performance of banks can helps them to compete and to achieve higher rate of return relative to cost, and at the same time to participate in economic development. Inefficient performance of banks, on the other hand, will lead to hinder economic activities in other sectors such as industry and services as banks are linked directly to the entire economy. Therefore, bank efficiency analysis is an important tool for government, regulators, banks management, stock market, and investors. Several approaches have been used to estimate banks' efficiency. One of these approaches is Data Envelopment Analysis (DEA) which has been used extensively to evaluate the efficiency of banking institutions, hospitals and other institutions. This study analyzes the technical efficiency of Saudi banks during the period of 2007-2011 by using the Data Envelopment Analysis (DEA) technique. This study provides a deep understanding of the importance of maintaining the efficiency of the banking sector for sustained economic development. This will also examine the stability of bank efficiencies over time for the studied period. The study contributes to the growing existing empirical literature on banking efficiency in developing countries, particularly in the Middle East. The study is also important as it covers all the local commercial and Islamic banks in Saudi Arabia during the period of study. Furthermore, it has another significant contribution as it may reflect the effect of deregulation in the banking sector, which was not really covered in previous studies. It will also provide crucial information about Saudi banks' financial conditions and management performance for the benefit to a number of interest groups and policy-makers including the Saudi government, the Saudi Arabian Monetary Agency (SAMA), Saudi stock exchange (Tadawul), banks 
managers, as well as people dealing with banks and bank stock investors. Moreover, the results of this study would provide us explicit indications as to whether the Saudi banks are efficient in the global financial conditions. Despite the vast number of studies that focus on the efficiency of the banking sector, to the researcher's best knowledge, only a few studies were carried out in devel oping countries. The majority were carried out in developed countries, with particular emphasis on the banking sector in the United States. However, studies focused on the banks relative efficiency in the Middle East countries are very limited, and there is scarcity of research in the Arab countries, especially in Saudi Arabia. Therefore, this study will try to fill the gap in the literature. In addition, it will examine the impact of bank's size and capital adequacy on the Saudi banks efficiency. The remainder of this study is organized as follows: Part II reviews the importance of the study. Part III presents the relevant literature of the study. Part IV is devoted to the data, methodology. While part $\mathrm{V}$, empirical results and analysis of the findings. Finally, part VI concludes the study and provides some recommendations.

\section{Literature Review}

Zeitun and Benjelloun (2013) measured and evaluated the relative efficiency of 12 Jordanian banks over the period 2005-2010 by using Data Envelopment Analysis (DEA). Constant return to scale (CRS) and variable return to scale (VRS) were used in order to measure the relative efficiency. The result of the study showed that, on the technical efficiency scale only a few Jordanian banks were efficient in managing their financial resources and generating profit. Furthermore, few banks were found to be efficient on the scale of pure technical efficiency and only so in a few years. Moreover, the financial crisis was found to have a significant impact on banks' efficiency.

Karimzadeh (2012) examined the efficiency of Indian commercial banks during 2000 - 2010 by utilizing Data Envelopment Analysis (DEA). Inputs and outputs of the study were analyzed based on intermediation approach based on the sample of 8 commercial banks, The result of the study revealed that the mean of cost (economic) efficiency, technical efficiency, and a locative efficiency are 0.991, 0.995, and 0.991 in VRS model and 0.936. 0.969, and 0.958 in CRR model, respectively using DEA approach. In addition, the results suggest that Bank of India and $\mathrm{ICICl}$ bank are more efficient as compare to other banks in India and result confirmed that selected Public Sector Banks are more efficient than Private sectors during the study period in India.

Zainal and Ismail (2012) in their study examined the efficiency of Islamic banks in Malaysia in the year 2006 till 2010. The aims of the study were to calculate technical efficiency (TE), pure technical efficiency (PTE) and scale efficiency (SE) of Islamic banks, and to compare the efficiency scores between local and foreign Islamic banks. A non-parametric based Data Envelopment Analysis (DEA) was used to estimate the efficiency using input orientation. Inputs and outputs of this study were analyzed based on intermediation approach. The results showed that the average TE, PTE and SE were $0.79,0.90$ and 0.88 respectively. Next, local Islamic banks scored higher TE and SE compared to foreign Islamic banks. But foreign Islamic banks scored higher PTE than that of Islamic banks.

Noor and Ahmad (2012) investigated the efficiency of the Islamic banking sector in 25 countries during the period 1992-2009 using data for 78 Islamic banks. The efficiency estimated of individual banks was evaluated using the nonparametric Data Envelopment Analysis (DEA) method. The empirical findings seem to suggest that the world Islamic banks have exhibited high pure technical efficiency. pure technical inefficiency was found to have greater influence in determining the total technical inefficiency. Secondly, it is suggested that further analysis of the world Islamic banking sector's efficiency should consider specific factors rela ting to high-income countries' leading the efficiency over the years compared to banks operating in middle and low-income countries. The results showed a positive relationship between bank efficiency and size and profitability, while a negative relationship between bank efficiency and loans intensity and capitalization. A multivariate analysis based on the Tobit model reinforces these findings specifically for profitability. The return on equity had a positive but statistically insignificant relationship with bank efficiency. The finding implied that the higher the return on equity, the higher the bank productivity growth will be.

Akhtar and Sadaqat (2011) attempted to investigate the impact of how the bank-specific factors of profitability affect the performance of Islamic banks. Sample that is composed of Islamic banks of Pakistan from period 2006 to 2009 were used. In his study It was evident from both statistical multivariate regression models that the relationship of gearing ratio and capital adequacy ratio found to have a positive relation and 
are statistically significant at the $5 \%$ significance level, whereas the asset management is statistically significant in model I and insignificant in model II with positive relation in both models. Size of the ban $\mathrm{k}$ reported negative and insignificant relation in both models, which can be explained with the fact that most of the Islamic banks were facing losses in recent years. Moreover capital adequacy found to have significant relation in both models, as prudential regulations tighten by the State bank of Pakistan.

Noor et al, (2011) investigated the efficiency of the Islamic banking sectors in 4 Asian countries namely Bangladesh, Indonesia, Malaysia and Pakistan during the period of 2001-2006. The efficiency estimated of individual banks was evaluated by using the non-parametric Data Envelopment Analysis (DEA) method. The results implied that during the period of study, although the Asian Islamic banking sectors have been operating at a relatively optimal scale of operations, they were relatively managerially inefficiency in controlling their operating costs and utilizing their resources to the fullest.

Ajlouni and Hmedat (2011) measured the relative efficiency of banks in Jordan using DEA. Also, they investigated the determinants of such efficiency, in terms of bank size and capitalization. The duration of the measured performance of their study was is (2005-2008). The results of their study indicate that average efficiency score of the sample banks is high and stable over time. Another important result was that the relative efficiency of larger banks significantly outperforms smaller and medium size banks, indicating that bank size is a determinant of efficiency. However, banks with higher capital adequacy ratio were less efficient. They concluded that commercial banks in Jordan with higher capital adequacy ratio are risk-averse and managing safer and lower-earning portfolios.

AlKhathlan and Malik (2010) studied the efficiency of Saudi banks by using Data Envelopment Analysis (DEA) models like; Charnes-Cooper-Rhodes (CCR) and Banker-Charnes-Cooper (BCR). The paper covered 10 out of 12 operating banks in Saudi industry from 2003 through 2008. The empirical results showed that most of Saudi banks do have efficient financial resources by 86.17 percent and 93.97 per cent as per CCR and BCR approach respectively.

Khaddaj (2010) investigated the efficiency level of the Syrian private banks during the period 2006 to 2009 by using Data Envelopment Analysis. A total of 10 banks were evaluated by using four models to analyze the relative efficiency of each bank based on its operating and intermediation levels. The findings revealed that in spite of the fact that most Syrian banks were inefficient on their operating level, they tend to be more efficient in their intermediation role. Accordingly, the Syrian Banks could further utilize their resources to generate more revenues and/or reduce their expenses in order to reach the efficiency frontier. Furthermore, this study had investigated the effects of banks age on their relative efficiency, where it had been found that most of the banks efficiency scores would rise after accounting for banks years of operation as an uncontrolled input; Thus indicating an indirect positive effect the banks' age had on the overall efficiency. In other words, most of the observed Syrian banks have managed to utilize their years of operation in generating revenues, facilities and investments.

Al-Jarrah (2007) stated that The Data Envelopment Analysis (DEA) approach is used to investigate cost efficiency levels of banks operating in Jordan, Egypt, Saudi Arabia and Bahrain over 1992-2000. The estimated cost efficiency is further decomposed into technical and allocative efficiency at both variable and constant return to scale. Later on, the technical efficiency is further decomposed into pure technical and scale efficiency. Our cost efficiency scores ranged from 50 to $70 \%$ with some variations in scores depending on bank's size and its geographical locations. These results suggest that the same level of output could be produced with approximately $50-70 \%$ of their current inputs if banks under study were operating on the most efficient frontier.

\section{Overview of Saudi Banking System}

The Saudi banking system has undergone substantial changes over the last decade. There is no doubt that in Kingdom of Saudi Arabia (KSA) without exception, banking system has a significant weight in the Middle East. The gradual deregulation process of financial services allowed foreign financial institutions to provide financial services in Saudi Arabia. As a reaction to this process, domestic Saudi banks have also introduced a large scale of new products and services. Saudi Banks have expanded their operations and have taken advantage of scale and scope of economies as well as product diversification. Consequently, consolidated competition, effective resources allocation, producing innovative products for saving money, 
and developing a new technology for evolving the quality have been focal points among banks in Saudi Arabian banking system, not only locally, but also worldwide. Therefore, there is an urgent need to make comprehensive analysis of Saudi Arabian banks' efficiency. However Saudi Arabian Monetary Agency-SAMA in its Forty-Fourth Annual Report (2008) summarized the performance of Saudi banks as follows: "Commercial banks recorded good growth rates in their financial positions during 2007. This was due to efficient management by commercial banks of their financial resources. Furthermore, as Al-Muharrami (2007) stated, the Saudi banking sector is the largest banking sector amongst the Gulf countries, and better level among Arab Countries. The main distinguished characteristic of the Saudi banking system is that Conventional and Islamic banks are operating side by side in Saudi Arabian industry for the sake of profit maximization. Thus, many conventional banks are providing Islamic windows to achieve higher market share. The proportion of Islamic banking has increased significantly. The banking industry in Saudi Arabia is one of the strongest industries in the Gulf country, as well as the most attractive economic sector within Saudi Arabia (Ahmed and Khababa, 1999). Moreover, according to Ford (2007), the Saudi banking sector is well-controlled and tightly organized and is strongly regulated. Although there was a financial crisis in 2007 and 2008, which affected the banking industry worldwide, a report by Ford and Siddiqi (2010) asserted that the Saudi banks remained in the top 65 Middle Eastem banks; moreover, three of them were in the top five banks. There are twelve banks in Saudi Arabia and all of them joined the Saudi stock market except one, which was owned by known traders. A 2009 report from Riyad Bank showed how the banking industry within Saudi Arabia had grown since it become a member of the G-20, which is a group of financial public organizations and central banks within 19 countries and the European Union.

\section{Research Methodology}

\subsection{Hypothesis}

It is important to conduct a deep investigation of the special features of the banking sector in Saudi Arabia, especially in term of its efficiency. The problem of this study is to measure whether Saudi banks perform efficiently, and what is the effect of such factors, as size and capital adequacy ratio on the level of bank efficiency. The present study seeks to test the following hypothesis:

H1: banks in Saudi Arabia are financially efficient.

H2: There is a significant difference between the efficiency of banks in Saudi Arabia due to their size (logarithm of total assets).

H3: There is a significant difference between the efficiency of banks in Saudi Arabia due to their capital adequacy (the ratio of equity to total assets).

\subsection{Data}

This study presents an analysis of only ten banks operating in Saudi Arabia during the period (20072011). All the banks listed in Saudi stock exchange (Tadawul) since 2005 were selected. This work is done in order to see the changes in efficiency of these banks during the study period. Table 1 present the Domestic Saudi Banks, and network of branches as on (2011).There are twelve Saudi banks operating in Saudi Arabia, two of them are excluded in this study, due to the fact that one of them is not listed in Saudi stock exchange (Tadawul), and the other one is a new one established in 2008. In obtaining the data, the author used the annual reports of these banks, their websites, and related web pages of Saudi stock exchange (Tadawul) and Saudi Arabian Monetary Agency (SAMA) on the internet.

Table 1. Domestic Saudi Banks, and network of branches (2011)

\begin{tabular}{|c|c|c|c|}
\hline Bank's Name & Date of Establishment & Abbreviation & branches \\
\hline National Commercial Bank & 1953 & NCB & 295 \\
\hline Riyad Bank & 1957 & RIBL & 248 \\
\hline Aljazira Bank & 1975 & BJAZ & 41 \\
\hline Alrajhi Bank & 1976 & RJHJ & 455 \\
\hline Saudi Investment Bank & 1976 & SAIB & 48 \\
\hline Samba Financial Group & 1980 & SAMBA & 69 \\
\hline
\end{tabular}




\begin{tabular}{|c|c|c|c|}
\hline Bank's Name & Date of Establishment & Abbreviation & branches \\
\hline Al-bilad Bank & 2004 & ALBI & 67 \\
\hline Alinma Bank & 2008 & ALINMA & 13 \\
\hline Saudi Hollandi Bank & 1926 & SHB & 44 \\
\hline Banque Saudi Fransi & 1977 & BSFR & 83 \\
\hline Arab national Bank & 1979 & ANB & 142 \\
\hline Saudi Arabian British Bank & 1978 & SABB & 80 \\
\hline
\end{tabular}

\subsection{Methodology}

This study will use the non - parametric frontier approach to estimate the relative efficiency of banks in Saudi Arabia. The objective of this study is to evaluate the relative efficiency of 10 Saudi banks over the period 2007-2011. No foreign banks were used in this study. The measurement of efficiency used in this study is the Data Envelopment Analysis approach. Abraham Charnes (1978) has coined the term data envelopment analysis (DEA). Charnes seminal paper is still one of the best sources of intuition into the method. Assume there are $n$ decision making units (DMU), denoted by subscript $\mathrm{i}$.

Maximize $\mathrm{E}_{\mathrm{k}}=\sum_{i=1}^{m} \mathrm{Vj}_{\mathrm{k}} \mathrm{Y}_{\mathrm{jk}}$

Subject to the constraints:

1) $\quad \sum_{i=1}^{m} \mathrm{U}_{\mathrm{ik}} \mathrm{X}_{\mathrm{ik}}=1$,

2) $\quad \sum_{j=1}^{n} \mathrm{~V}_{\mathrm{jk}} \mathrm{Y}_{\mathrm{jk}}-\sum_{i=1}^{m} \mathrm{U}_{\mathrm{ik}} \mathrm{X}_{\mathrm{ik}} \leq 0$

3) $\quad \mathrm{U}_{\mathrm{ik}} \geq 0$

4) $\quad V_{\mathrm{jk}} \geq 0$

$, i=1,2,------, m$

5) $\quad \sum_{i=1}^{m} \mathrm{U}_{\mathrm{ik}}=\sum_{j=1}^{n} \mathrm{~V}_{\mathrm{jk}}$

Where,

$\mathrm{V}_{\mathrm{jk}}=$ the weight placed on jth output $\left(Y_{j}\right)$ of the kth DMU.

$\mathrm{U}_{\mathrm{ik}}=$ the weight placed on ith input (Xi) of the kth DMU.

$\mathrm{X}_{\mathrm{ik}}=$ the ith input parameter $(\mathrm{X})$ of the kth DMU.

$\mathrm{Y}_{\mathrm{jk}}=$ the jth output parameter $(\mathrm{Y})$ of the kth DMU.

$E_{k}=$ the relative efficiency score of kth DMU.

Over the past two decades, DEA has become a popular methodology for evaluating the relative efficiencies of decision making units (DMUs). A DMU is an entity that produces outputs and uses up inputs, in this study, each bank constitutes a DMU. This study applies two basic Data Envelopment Analysis (DEA) models to evaluate the relative efficiency of Saudi Banks using annual data from 2007 through 2011. These are:

1. Charnes-Cooper-Rhodes (CCR) model which assumed constant returns to scale (CRS) to measure the relative efficiency of each DMU which is between 0 and 1 and can determine whether a DMU is in constant, increasing or decreasing returns to scale.

2. Banker-Charnes-Cooper (BCC) model which widened the CCR model to account for variable returns to scale (VRS).This approach forms a convex hull of intersecting planes which envelope the data points more tightly than the CRS conical hull and thus provides technical efficiency scores which are greater than or equal to those obtained using the CRS model.

To model the bank production process intermediation approach was followed (see Charnes) which takes banks as entities using, two inputs and two outputs for each bank. These are:

1. Input $1(x 1)=$ Total deposits

2. Input $2(x 2)=$ Total expense (Interest and non-interest expenses)

3. Output $1(\mathrm{y} 1)=$ Total loans and advances

4. Output $2(\mathrm{y} 2)=$ Net investment 
Table 2 provides some relevant statistics of key variables in the sample.

Table 2. Average Statistics of Inputs and Outputs of Banks in Saudi for the Period (2007-2011)

\begin{tabular}{|l|c|c|c|c|}
\hline \multirow{2}{*}{$\begin{array}{c}\text { Bank Name } \\
\text { (in Million SAR) }\end{array}$} & \multicolumn{2}{c|}{ INPUTS } & \multicolumn{2}{c|}{ OUTPUTS } \\
\cline { 2 - 5 } & $\begin{array}{c}\text { Total } \\
\text { Deposits }\end{array}$ & $\begin{array}{c}\text { Total } \\
\text { Expense }\end{array}$ & $\begin{array}{c}\text { Total } \\
\text { Loans }\end{array}$ & $\begin{array}{c}\text { Total } \\
\text { Investment }\end{array}$ \\
\hline Riyad Bank & 116286564 & 2698096 & 97858477.6 & 34231470.2 \\
\hline Saudi Arabian British Bank & 93862610 & 2434006.2 & 75535797.4 & 23284077.6 \\
\hline Banque Saudi Fransi & 92305662 & 1529048.2 & 78466650.4 & 20410834.2 \\
\hline Hollandi Bank Bank & 41814531 & 1288983.2 & 34875793.6 & 13351005.2 \\
\hline Arab national Bank & 84234652 & 2052002.2 & 68328255 & 26485610.8 \\
\hline Samba Financial Group & 133577667 & 2446275 & 86441853.2 & 56370380.2 \\
\hline Aljazira Bank & 23638674 & 946916.6 & 16505675.2 & 4819950.8 \\
\hline Alrajhi Bank & 129138310 & 4334864 & 1228229.4 & 144773437.2 \\
\hline Saudi Investment Saudi & 37140745 & 1149699.2 & 28117011.4 & 11761819.4 \\
\hline Al-bilad Bank & 15470261 & 932496.6 & 10309693.2 & 1465955.8 \\
\hline average & 76746968 & 1981238.72 & 49766743.64 & 33695454.14 \\
\hline
\end{tabular}

The researcher ran the DEA model separately for each year using input-orientation. By running these programs with the same data under constant returns-to-scale (CRS) and variable returns-to-scale (VRS) assumptions, measures of overall technical efficiency and 'pure' technical efficiency are obtained. In order to obtain a measure of scale efficiency, the overall technical efficiency was divided by pure technical efficiency. The DEA selects weights so that the ratio of outputs to inputs for all DMUs is less than or equal to one. However, it selects those weights in order to make the output to input ratio for one particular DMU (the DMU in the objective function) as high as possible. If the ratio for that particular DMU is less than one (1), then, with the same weights, one or more other DMUs must equal one. Thus, those other DMUs are more efficient. The resultant ratio for DMU is a measure of distance from the production possibilities frontier. A ratio of 1 or $100 \%$ indicates DMU lies squarely on the frontier and operations on the frontier, hence and full efficiency. A ratio of less than 1 or $100 \%$ reflects operations below the frontier. The lower the ratio, the further the DMU lies from the frontier, hence inefficient (Ajlouni and Tobaishat, 2010).

\section{Results and Discussion}

\subsection{DEA efficiency scores based on constant returns to scale (CCR Model)}

DEA efficiency scores based on constant returns to scale (CCR Model) are shown in Table 3. Average technical efficiency in the Saudi banks during the study period ranges from $95.30 \%$ (2010) to $99.28 \%$ (2008) with average $95.52 \%$. ANB and SAMBA were the only two banks with efficiency scores of $100 \%$ in four years during the study period, implying that they are on the efficiency frontier and were peers (or bench marked) during the study period. In 2007, six banks emerged on the efficient frontier, indicating efficient management by $60 \%$ of Saudi banks of their financial resources. Although, BLAD, and RBIL are having efficiency scores less than $90 \%$ indicating that $10 \%$ of Saudi banks are inefficient and requires further probing. However, in 2011, five banks emerged on the efficient frontier, indicating efficient management by $50 \%$ of Saudi banks of their financial resources. It is worth mentioned that all banks in 2011 are having efficiency scores more than $94.85 \%$, which indicate that Saudi banks have improved their efficiency during the study period. BSFR is ranked in the first position among all the listed banks based on their average efficiency (99.92\%) during the study period and SHP ranked in the last position on their average efficiency (94.23\%).

Table 3. DEA Efficiency Scores of the Selected Banks Based on Constant Returns to Scale (CCR Model) (2007-2011)

\begin{tabular}{|c|c|c|c|c|c|c|c|c|}
\hline \multirow{2}{*}{ DMU No. } & \multirow{2}{*}{$\begin{array}{c}\text { DMU } \\
\text { Name }\end{array}$} & \multicolumn{5}{|c|}{ Input-Oriented CRS Efficiency } & \multirow{2}{*}{ average } & \multirow{2}{*}{ Rank } \\
\cline { 3 - 8 } & NaNB & $100.00 \%$ & $100.00 \%$ & $97.44 \%$ & $100.00 \%$ & $100.00 \%$ & $99.49 \%$ & 2 \\
\hline 1 & BJAZ & $100.00 \%$ & $100.00 \%$ & $96.66 \%$ & $94.39 \%$ & $100.00 \%$ & $98.21 \%$ & 4 \\
\hline 2 & &
\end{tabular}


International Journal of Academic Research in Accounting, Finance and ManagementSciences Vol.3 (3), pp.152-161, (c) 2013 HRMARS

\begin{tabular}{|c|c|c|c|c|c|c|c|c|}
\hline \multirow{2}{*}{ DMU No. } & \multirow{2}{*}{$\begin{array}{l}\text { DMU } \\
\text { Name }\end{array}$} & \multicolumn{5}{|c|}{ Input-Oriented CRS Efficiency } & \multirow{2}{*}{ average } & \multirow{2}{*}{ Rank } \\
\hline & & 2007 & 2008 & 2009 & 2010 & 2011 & & \\
\hline 3 & BLAD & $78.48 \%$ & $100.00 \%$ & $100.00 \%$ & $100.00 \%$ & $94.09 \%$ & $94.51 \%$ & 9 \\
\hline 4 & BSFR & $100.00 \%$ & $100.00 \%$ & $98.49 \%$ & $99.61 \%$ & $100.00 \%$ & $99.62 \%$ & 1 \\
\hline 5 & RIBL & $87.00 \%$ & $100.00 \%$ & $98.39 \%$ & $91.00 \%$ & $96.39 \%$ & $94.55 \%$ & 8 \\
\hline 6 & RJHJ & $100.00 \%$ & $100.00 \%$ & $100.00 \%$ & $87.03 \%$ & $97.23 \%$ & $96.85 \%$ & 6 \\
\hline 7 & SABB & $99.67 \%$ & $100.00 \%$ & $92.79 \%$ & $85.63 \%$ & $100.00 \%$ & $95.62 \%$ & 7 \\
\hline 8 & SAIB & $100.00 \%$ & $92.84 \%$ & $100.00 \%$ & $100.00 \%$ & $98.66 \%$ & $98.30 \%$ & 3 \\
\hline 9 & SAMBA & $100.00 \%$ & $100.00 \%$ & $85.70 \%$ & $100.00 \%$ & $100.00 \%$ & $97.14 \%$ & 5 \\
\hline 10 & SHP & $90.09 \%$ & $100.00 \%$ & $90.92 \%$ & $95.29 \%$ & $94.85 \%$ & $94.23 \%$ & 10 \\
\hline \multicolumn{2}{|c|}{ Mean Efficiency } & $95.52 \%$ & $99.28 \%$ & $96.04 \%$ & $95.30 \%$ & $98.12 \%$ & \multicolumn{2}{|c|}{$95.52 \%$} \\
\hline \multicolumn{2}{|c|}{$\min$} & $78.48 \%$ & $92.84 \%$ & $85.70 \%$ & $85.63 \%$ & $94.09 \%$ & \multicolumn{2}{|c|}{$94.23 \%$} \\
\hline \multicolumn{2}{|c|}{$\max$} & $100.00 \%$ & $100.00 \%$ & $100.00 \%$ & $100.00 \%$ & $100.00 \%$ & \multicolumn{2}{|c|}{$99.62 \%$} \\
\hline
\end{tabular}

\subsection{DEA efficiency scores based on variable returns to scale (BCC Model)}

Table 4 presents DEA efficiency scores based on variable returns to scale (BCC Model) for each year, it is clear from the table that the mean efficiency in the Saudi banks during the study period ranges from $96.49 \%$ (2010) to $100 \%$ (2007 and 2008).The average efficiency during the study period for all banks were $98.55 \%$. BLAD was the only bank with efficiency scores of $100 \%$ for all years, implying that it is on the efficiency frontier and was peers (or bench marked) during the study period. In 2007and 2008, all banks emerged on the efficient frontier, indicating efficient management by majority (100\%) of Saudi banks of their financial resources. In 2011, eight banks emerged on the efficient frontier, indicating efficient management by majority $(100 \%)$ of Saudi banks of their financial resources. However the remaining banks having efficiency scores more than $95.05 \%$ were SAIB (99.02\%) and SHP (95.05\%), which indicates that Saudi banks have improved their efficiency during the study period. BLAD is ranked in the first position among all the listed banks based on their average efficiency of (100\%) during the study period. SABB ranked in the last position on their average efficiency with (95.83\%).

Table 4. DEA Efficiency Scores of the Selected Banks Based on Variable Returns to Scale (BCC Model) (2007-2011)

\begin{tabular}{|c|c|c|c|c|c|c|c|c|}
\hline \multirow{2}{*}{ DMU No. } & \multirow{2}{*}{ DMU Name } & \multicolumn{9}{|c|}{ Input-Oriented VRS Efficiency } & \multicolumn{2}{|c|}{ Average } \\
\cline { 3 - 9 } & & 2007 & 2008 & 2009 & 2010 & 2011 & \multicolumn{2}{|c|}{} \\
\hline 1 & ANB & $100.00 \%$ & $100.00 \%$ & $97.45 \%$ & $100.00 \%$ & $100.00 \%$ & $99.49 \%$ & 5 \\
\hline 2 & BJAZ & $100.00 \%$ & $100.00 \%$ & $96.70 \%$ & $94.42 \%$ & $100.00 \%$ & $98.22 \%$ & 6 \\
\hline 3 & BLAD & $100.00 \%$ & $100.00 \%$ & $100.00 \%$ & $100.00 \%$ & $100.00 \%$ & $100.00 \%$ & 1 \\
\hline 4 & BSFR & $100.00 \%$ & $100.00 \%$ & $99.20 \%$ & $99.62 \%$ & $100.00 \%$ & $99.77 \%$ & 3 \\
\hline 5 & RIBL & $100.00 \%$ & $100.00 \%$ & $100.00 \%$ & $98.07 \%$ & $100.00 \%$ & $99.61 \%$ & 4 \\
\hline 6 & RJHJ & $100.00 \%$ & $100.00 \%$ & $100.00 \%$ & $88.79 \%$ & $100.00 \%$ & $97.76 \%$ & 8 \\
\hline 7 & SABB & $100.00 \%$ & $100.00 \%$ & $92.84 \%$ & $86.32 \%$ & $100.00 \%$ & $95.83 \%$ & 10 \\
\hline 8 & SAIB & $100.00 \%$ & $100.00 \%$ & $100.00 \%$ & $100.00 \%$ & $99.02 \%$ & $99.80 \%$ & 2 \\
\hline 9 & SAMBA & $100.00 \%$ & $100.00 \%$ & $89.82 \%$ & $100.00 \%$ & $100.00 \%$ & $97.96 \%$ & 7 \\
\hline 10 & SHP & $100.00 \%$ & $100.00 \%$ & $92.38 \%$ & $97.63 \%$ & $95.05 \%$ & $97.01 \%$ & 9 \\
\hline Mean Efficiency & $100.00 \%$ & $100.00 \%$ & $96.84 \%$ & $96.49 \%$ & $99.41 \%$ & $98.55 \%$ & \\
\hline \multicolumn{2}{|c|}{ min } & $100.00 \%$ & $100.00 \%$ & $89.82 \%$ & $86.32 \%$ & $95.05 \%$ & $95.83 \%$ & \\
\hline \multicolumn{2}{|c|}{ max } & $100.00 \%$ & $100.00 \%$ & $100.00 \%$ & $100.00 \%$ & $100.00 \%$ & $100.00 \%$ \\
\hline
\end{tabular}

\subsection{Decomposing Technical Efficiency into Pure Technical Efficiency \& Scale Efficiency}

Table 5 shows the mean efficiency for each year by decomposing technical efficiency into pure technical efficiency and scale efficiency. The average index of technical efficiency during the study period varies between $95.30 \%$ and $99.28 \%$, as well for the pure technical efficiency varying at $96.49 \%$ to $100.00 \%$, and of scale efficiency also varies at $95.5 \%$ to $100.00 \%$. Decomposing technical efficiency into pure technical 
efficiency and scale efficiency allows us to gain insight into the main sources of inefficiencies. The results of the analysis presented in Table $4 \& 5$ prove that banks in Saudi Arabia are efficient.

Table 5. DEA Mean Efficiency Scores of the Selected Banks (2007-2011)

\begin{tabular}{|c|c|c|c|}
\hline Year & Mean Technical( CRS) & Input-Oriented Mean(VRS) & Mean Scale efficiency \\
\hline 2007 & $95.52 \%$ & $100.00 \%$ & $95.5 \%$ \\
\hline 2008 & $99.28 \%$ & $100.00 \%$ & $100.0 \%$ \\
\hline 2009 & $96.04 \%$ & $96.84 \%$ & $98.4 \%$ \\
\hline 2010 & $95.30 \%$ & $96.49 \%$ & $97.3 \%$ \\
\hline 2011 & $98.12 \%$ & $99.41 \%$ & $98.8 \%$ \\
\hline
\end{tabular}

\subsection{Analysis of Efficiency Determinants}

\subsubsection{Relative efficiency and the impact of bank size}

The second hypothesis articulated that there is a significant difference between the efficiency of Banks in Saudi Arabia due to their size (logarithm of total assets). Thus, for the analyzes purpose Saudi banks were classified into large banks, medium banks, and small banks. Large banks include banks with logarithm of total assets not less than 16.50, such as RJHJ and SAMBA; medium banks include banks with logarithm of total assets between 15.5 and16.49, such as RIBL, SABB, BSFR, ANB, SHB; and small banks include banks with logarithm of total assets less than 15.5 , includes SAIB, BJAZ and BLAD.

Table 6 presents the result of the analysis of the relative efficiency of banks in Saudi Arabia categorized by size via the operating approach. It was found that, on average small banks are the most efficient banks and have average efficiency scores of 99.34\% during (2007-2011). However, medium banks with average (97.79\%) and large banks averages (97.00\%) are considered to be efficient during the study period. Furthermore, the medium banks are more efficient than the large banks.

The above results implying that small banks could perform the role of financial intermediaries, using labors and capitals to transfer deposits into loans and investments, more efficiently than large and medium ones. This is not a surprising result, because revenues of commercial banks come from two major sources which are interest incomes and non-interest incomes (Ajlouni, Hmedat, 2011). Hence, the second hypothesis of the study is proved.

Table 6. The Relative Efficiency of Selected Banks Categorized by Size (2007-2011)

\begin{tabular}{|c|c|c|c|c|c|c|c|c|}
\hline Bank size & Bank & LOG Assets & $\mathbf{2 0 0 7}$ & $\mathbf{2 0 0 8}$ & $\mathbf{2 0 0 9}$ & $\mathbf{2 0 1 0}$ & $\mathbf{2 0 1 1}$ & Average \\
\hline \multirow{3}{*}{ Large Banks } & RJHJ & 16.58 & $100.00 \%$ & $100.00 \%$ & $100.00 \%$ & $87.03 \%$ & $97.23 \%$ & $97.00 \%$ \\
\cline { 2 - 8 } & SAMBA & 16.54 & $100.00 \%$ & $100.00 \%$ & $85.70 \%$ & $100.00 \%$ & $100.00 \%$ & \\
\hline \multirow{5}{*}{ Medium Banks } & RIBL & 16.47 & $100.00 \%$ & $100.00 \%$ & $100.00 \%$ & $98.07 \%$ & $100.00 \%$ & \multirow{5}{*}{$97.79 \%$} \\
\cline { 2 - 8 } & SABB & 16.24 & $100.00 \%$ & $100.00 \%$ & $92.84 \%$ & $86.32 \%$ & $100.00 \%$ & \\
\cline { 2 - 8 } & BSFR & 16.23 & $100.00 \%$ & $100.00 \%$ & $99.20 \%$ & $99.62 \%$ & $100.00 \%$ \\
\cline { 2 - 8 } & ANB & 16.12 & $100.00 \%$ & $100.00 \%$ & $97.44 \%$ & $100.00 \%$ & $100.00 \%$ \\
\cline { 2 - 8 } & SHP & 15.51 & $90.09 \%$ & $100.00 \%$ & $90.92 \%$ & $95.29 \%$ & $94.85 \%$ & \\
\hline \multirow{3}{*}{ Small Banks } & SAIB & 15.42 & $100.00 \%$ & $100.00 \%$ & $100.00 \%$ & $100.00 \%$ & $99.02 \%$ & \multirow{2}{*}{$99.34 \%$} \\
\cline { 2 - 8 } & BJAZ & 15.07 & $100.00 \%$ & $100.00 \%$ & $96.70 \%$ & $94.42 \%$ & $100.00 \%$ \\
\cline { 2 - 7 } & BLAD & 14.74 & $100.00 \%$ & $100.00 \%$ & $100.00 \%$ & $100.00 \%$ & $100.00 \%$ & \\
\hline
\end{tabular}

\subsubsection{Difference between the efficiency of banks due to their capital adequacy}

The third hypothesis stated that: There is a significant difference between the efficiency of banks in Saudi Arabia due to their capital adequacy (the ratio of Equity to Total Assets). The impact of banks' capital adequacy on the efficiency of banks in Saudi Arabia can be proxy by the ratio of equity to total assets (EQ/TA). This ratio indicates capital strength or bank safety and soundness. Banks in Saudi banks are classified according to the capital adequacy ratio into two groups:

1. Meeting the average ratio and above during the study period (2007-2011).

2. Meeting below the average ratio during the study period (2007-2011). 
Table 7 shows the calculated EQ/TA ratio for each bank in the sample. As shown in the Table 7, only sex banks of the sample did not meet the average ratio and above during the study period (2007-2011) of 13.7\%, while the remaining four banks met such average. However, all banks in Saudi Arabia met the minimum capital adequacy ratio level of Basel, which is $8 \%$.

Table 7. Capital Adequacy (EQ/TA) Average Ratio for Selected Banks (2007-2011)

\begin{tabular}{|c|c|c|c|}
\hline DMU Name & Average Total Assets & Total Equity & EQ/TA \\
\hline RIBL & 162369285.6 & 25300852.6 & $15.6 \%$ \\
\hline SABB & 124148387.2 & 13488440.2 & $10.9 \%$ \\
\hline BSFR & 121994719.4 & 15743985.2 & $13.3 \%$ \\
\hline SHB & 56477676 & 7501004.8 & $11.7 \%$ \\
\hline SAIB & 50744596.6 & 5938009 & $12.4 \%$ \\
\hline ANB & 111936218.6 & 13895898.6 & $12.7 \%$ \\
\hline SAMBA & 179802632.6 & 22781418.2 & $15.4 \%$ \\
\hline BJAZ & 30195353.6 & 4652166.8 & $16.5 \%$ \\
\hline RJHJ & 173240066.8 & 28503528.2 & $16.0 \%$ \\
\hline BLAD & 19788534.8 & 3167668 & $13.7 \%$ \\
\hline Average & 14097297.16 & 103069747.1 & \\
\hline
\end{tabular}

The results of the analysis of the relative efficiency of banks in Saudi Arabia categorized by capital adequacy ratio via the operating approach are exhibited in Table 8. It is clear that on average, banks meeting the EQ/TA ratio and above is less efficient than those do not. The latter banks have the highest efficiency scores in every year during (2007-2011), implying that they are efficient and had produced their outputs on the efficiency frontier. This implies that banks in Saudi Arabia with higher capital adequacy ratio are riskaverse and prefer safer and lower-earning portfolios.

Table 8. The Relative Efficiency of Selected Banks Categorized by EQ/TA Ratio (2007-2011)

\begin{tabular}{|c|c|c|c|c|c|c|c|}
\hline Capital adequacy & Banks & 2007 & 2008 & 2009 & 2010 & 2011 & Average \\
\hline \multirow{4}{*}{ Average Ratio \& above } & RIBL & $87.00 \%$ & $100.00 \%$ & $98.39 \%$ & $91.00 \%$ & $96.39 \%$ & \multirow{4}{*}{$96.03 \%$} \\
\hline & BJAZ & $100.00 \%$ & $100.00 \%$ & $96.66 \%$ & $94.39 \%$ & $100.00 \%$ & \\
\hline & RJHJ & $100.00 \%$ & $100.00 \%$ & $100.00 \%$ & $87.03 \%$ & $97.23 \%$ & \\
\hline & BLAD & $78.48 \%$ & $100.00 \%$ & $100.00 \%$ & $100.00 \%$ & $94.09 \%$ & \\
\hline \multirow{6}{*}{ below the average ratio } & SABB & $99.67 \%$ & $100.00 \%$ & $92.79 \%$ & $85.63 \%$ & $100.00 \%$ & \multirow{6}{*}{$97.40 \%$} \\
\hline & BSFR & $100.00 \%$ & $100.00 \%$ & $98.49 \%$ & $99.61 \%$ & $100.00 \%$ & \\
\hline & $\mathrm{SHB}$ & $90.09 \%$ & $100.00 \%$ & $90.92 \%$ & $95.29 \%$ & $94.85 \%$ & \\
\hline & SAIB & $100.00 \%$ & $92.84 \%$ & $100.00 \%$ & $100.00 \%$ & $98.66 \%$ & \\
\hline & ANB & $100.00 \%$ & $100.00 \%$ & $97.44 \%$ & $100.00 \%$ & $100.00 \%$ & \\
\hline & SAMBA & $100.00 \%$ & $100.00 \%$ & $85.70 \%$ & $100.00 \%$ & $100.00 \%$ & \\
\hline
\end{tabular}

\section{Conclusion}

This study uses the two basic Data Envelopment Analysis (DEA) models i.e. CCR and BCR to investigate the relative efficiency of Saudi banks. The empirical results do confirm that majority of Saudi banks efficiently managed their financial resources and the mean efficiency during the study period 2007-2011 was $95.52 \%$ and $98.55 \%$ as per CCR and BCR approach respectively. In 2011, it was found in the study that, five banks as per the CCR score and eight banks as per BCC score were positioned on the efficient frontier. Moreover, it is worth mentioning that all banks in 2011 are having efficiency scores more than $94.85 \%$ as per the CCR score and $95.05 \%$ as per BCC. The empirical results also indicates that, small banks could perform the role of financial intermediaries, using labors and capitals to transfer deposits into loans and investments, because these banks proved to be more efficient than large and medium ones. The banks with high EQ/TA ratio are less efficient than the banks with low EQ/TA ratio, implying that they are efficient and had produced their outputs on the efficiency frontier. 
Based on the results of study, it is recommended that, less inefficient banks in Saudi Arabia need to improve their efficiency and performance, by either increasing their loans or net investment, and/or promoting their resources and utilization efficiency by better handling their total expenses. It is also recommended by the author to Saudi bank managers to use Data envelopment Analysis (DEA) in assessing and measuring performance.

\section{References}

1. Ahmed, A.M., \& Khababa, N. (1999). Performance of Banking Sector in Saudi Arabia. Journal of Financial Management \& Analysis, 12(2), 30. http://connection.ebscohost.com/c/articles/3756287/ performance-banking-sector-saudi-arabia

2. Ajlouni, M., \& Tobaishat, S. (2010). The effect of Technical Efficiency in Insurance Companies on Stock Performance: Data Envelopment Analysis, Evidence from Jordanian Companies Listed in Amman Stock Exchange. International Journal of Strategic Management, 10(1), 67-75. www.freepatentsonline.com/article/ International .../237305845.htmlý

3. Ajlouni, M., \& Hmedat, M. (2011). The Relative Efficiency of Jordanian Banks and its Determinants Using Data Envelopment Analysis. Journal of Applied Finance \& Banking, 1(3), 33-58. http://www.scienpress.com/Upload/JAFB/Nol\%201_3_3.pdf

4. Akhtar, M.A., \& Sadaqat, S. (2011). Factors Influencing the Profitability of Islamic Banks of Pakistan. International Research Journal of Finance and Economics, Issue (66), 125-132. http://www.eurojoumals.com/IRJFE 66 12.pdf

5. Alkhathlan, K., \& Malik, S. (2012). Are Saudi banks efficient? Evidence Using Data Envelopment Analysis (DEA). International journal of economics and finance. (2), 53-58. http://www.econbiz.de/en/search/ detailed-view/doc/are-saudi-banks-efficient-evidence-using-data-envelopment-analysis-dea-alkhathlankhalid/ $10009311057 /$ ?no cache $=1$

6. AL-Muharrami, S. (2009). The Competition and Market Structure in the Saudi Arabia Banking. Journal of Economic Studies, 36(5) 446-460. http://ipac.kacst.edu.sa/edoc/2007/162875 2.pdf

7. Charnes, A., Cooper, W., Rhodes E. (1978). Measuring the Efficiency of Decision Making Units. European Journal of Operations Research, 2(6), 429-444.

8. Ford, N., \& Siddiqi, M. (2010). Top 100 Banks. Middle East, (415), 25-29. www.ibraheem.ws/ benchmarking/ Benchnarking\%20Report.pdfý

9. Ford, N. (2007). Saudi Banking. Middle East, (376), 48-50. www.ibraheem.ws/ benchmarking/Benchnarking\%20Report.pdfý

10. Jarrah, I.M. (2007). The Use of DEA in measuring efficiency in Arabian banking. Banks and Bank Systems, 2 (4), 21-30. http://businessperspectives.org/journals free/bbs/2007/BBS_en_2007_4_Al-Jarrah.pdf

11. Karimzadeh, M. (2012). Efficiency Analysis by using Data Envelop Analysis Model: Evidence from Indian Banks. Int. J Latest Trends Fin. Eco. Sc., 2(3), 228-237.

12. Noor , M.,\& Ahmad, N. (2012). The Determinants of Efficiency of Islamic Banks. The IUP Journal of Bank Management; XI(2): 32-70. http://papers.ssm.com/sol3/papers.cfm?abstract_id=2161759

13. Noor, M., Ahmad, N., Sufian, A. (2011). The efficiency of Islamic banks: Empirical Evidence from the Asian Countries' Islamic Banking Sectors. MPRA2011. http://mpra.ub.uni-muenchen.de/31869/

14. Saudi Arabian Monetary Agency. (2008). 44th Annual Report. http://www.sama.gov.sa/sites/ samaen/ReportsStatistics/Pages/AnnualReport.aspx

15. Khaddaj, W.W. (2010). Evaluating Banks Efficiency in Syria: An Empirical Study Using Data Envelopment Analysis. Social Science Research Network, 1-23. http://ssm.com/abstract=1876475 or http://dx.doi.org/10.2139/ssrn.1876475

16. Zainal, S., \& Ismail, M. (2012). Islamic Banking Efficiency: A DEA Approach. 3rd International Conference on Business and Economic Research (3rd ICBER). http://www.internationalconference.com.my/ proceeding/3rd icber2012 proceeding/136 388 3rdICBER2012 Proceeding PG1952 1965.pdf

17. Zeitun, R., \& Benjelloun, H. (2013). The Efficiency of Banks and the Financial Crisis in a Developing Economy: The Case of Jordan. Journal of Finance, Accounting and Management, 4(1), 1-20 http://www.gsmi-ijgb.com/Documents/JFAM\%20V4\%20N1\%20P01\%20-Rami\%20Zeitun\%20-

Efficiency\%20of\%20Banks.pdf 